\title{
Movement of Crop Protection Chemicals in Different Environmental Components
}

Geeta Singh*

DOI: 10.18811/ijpen.v5i03.9

\begin{abstract}
By the year 2050, the world population is estimated to reach 9.1 billion, which in-turn will increase demand for food production by $70 \%$ in developing countries. To fulfill the food security requirement over 1 billion population India need to produce an additional 5 million tons per year for the next 20 years to meet its food grain need of 300 million by 2020. Crop protection chemicals or pesticides are inherently toxic and therefore harmful for other non target organisms. The risk posed by these chemicals increased many-folds due to the fact that they do not stay at the intended target surface. Various mechanisms are involved in the movement of pesticides in different environmental components i.e., air, soil and water. Global literature survey showed that synthetic pesticides have potential risk to human and other life forms and unwanted side effects to the environment. In this paper, various studies are reviewed with the aim to understand the factors determining the occurrence of pesticides in far away places and disturbing ecological balance.
\end{abstract}

Keywords: Degradation, Leaching, Movement, Pesticides, Sorption.

International Journal of Plant and Environment (2019)

\section{INTRODUCTION}

hemicals, more commonly known as "Pesticides" are used to - protect crops because of their ability to kill, mitigate or repel any undesirable living being (termed as Pest). In the last 60 years the use of pesticides has greatly increased the crop yield and ushered "Green Revolution". Farming now-a-days rely heavily on use of various crop protection chemicals. Top pesticides producing countries are United States, Japan and China. Per hectare use of pesticides in countries like China and Japan is as high as $11-13 \mathrm{Kg}$. In India though per hectare consumption is low $(0.6 \mathrm{Kg} / \mathrm{ha})$, it has increased many folds in last 50 years (FICCl, 2018). The ever increasing reliance of farming on the use of chemicals can be attributed partially to the ever increasing demand for food by growing population. In India as many as 292 pesticides are registered for use in agricultural farms, food storage as well as household. An analysis by PAN India revealed that more than 115 pesticides out of the 292 are highly hazardous (Kumar and Narsimhareddy, 2017).

Most of these plant protection chemicals are not selective in their action and therefore equally harmful to non-targeted organisms also. For instance, insecticides are often just as toxic for beneficial insect species (honey bees, wild bees, butterflies, etc.) as they are for pest insects, thus disturbing ecological balance. Plenty of evidences have been documented in numerous scientific literatures mentioning various environmental hazards caused by the use of pesticides (Sparling et al., 2001). Exposure to pesticides poses serious health hazards in human being as well even at low concentrations (Doull, 1989; Jin-Clark et al., 2002; NicolopoulouStamati et al., 2016; Mesnage et al., 2018). The most common short term health hazards are itching, headache, tiredness, skin sore and blurred vision (Yadav and Dutta, 2019). Long term health hazards include cancer, immune deficiency, hormonal imbalance and birth defects. Further, the harmful effects of such pesticides are not restricted to the area of their application. Pesticides have been reported in rivers (Agnihotri et al., 1994; Dwivedi et al., 2018), groundwater (USEPA, 1990), and faraway places like North Pole (Wania, 2003).

Despite the lurking risk to health and strong criticism by environmental protection activists, the use of chemical pesticide would have to continue to feed increasing human population. The need of the hour is to regulate and optimize the application
Department of Chemistry, Deen Dayal Upadhyay Gorakhpur University, Gorakhpur-273009, Uttar Pradesh, INDIA

Corresponding Author: Dr. Geeta Singh, Department of Chemistry, Deen Dayal Upadhyay Gorakhpur University, Gorakhpur-273009, Uttar Pradesh, INDIA, Mob.: +91-9891819180, Email: geetasanger@gmail. com

How to cite this article: Singh, G. (2019). Movement of Crop Protection Chemicals in Different Environmental Components. International Journal of Plant and Environment 5(3): 206-209.

Source of support: Nil

Conflict of interest: None

Submitted:22.06.2019 Accepted:31.07.2019 Published:31.07.2019

of pesticides in best possible way. The basis of such decision making is the understanding of field scale processes governing the persistence and movement of pesticides in different environmental components i.e. air, soil and water.

\section{Distribution of Pesticide between air, soil and water}

Pesticide fate is controlled by numerous simultaneous biological, physical, and chemical reactions. As pesticide is applied on the targeted crop, it distributes itself in the air, soil, water, plants, and animals. Different natural phenomena are in operation for the movement of chemicals between environmental compartments (Fig. 1). Spray drift by wind and surface runoff are responsible for long distance movement (Rial-Otero et al., 2003). The primary factors governing such movement are the intensity, duration, and timing of the wind and rainfall events relative to application. Once on the soil surface, pesticides degrade in situ or move away by leaching into groundwater, runoff into adjacent streams, and/or volatilization into the atmosphere. The degree to which a pesticide is distributed between solid, liquid, and vapour phases strongly influences its subsequent dispersal into the environment (Taylor and Spencer, 1990; Jury and Flühler, 1992; Cousins et al., 1999).

\section{Soil-pesticide interaction}

Soil act as an interface for the movement of pesticides in air and water. Hence the interaction of pesticide and soil particles is important in deciding its fate in the environment. 


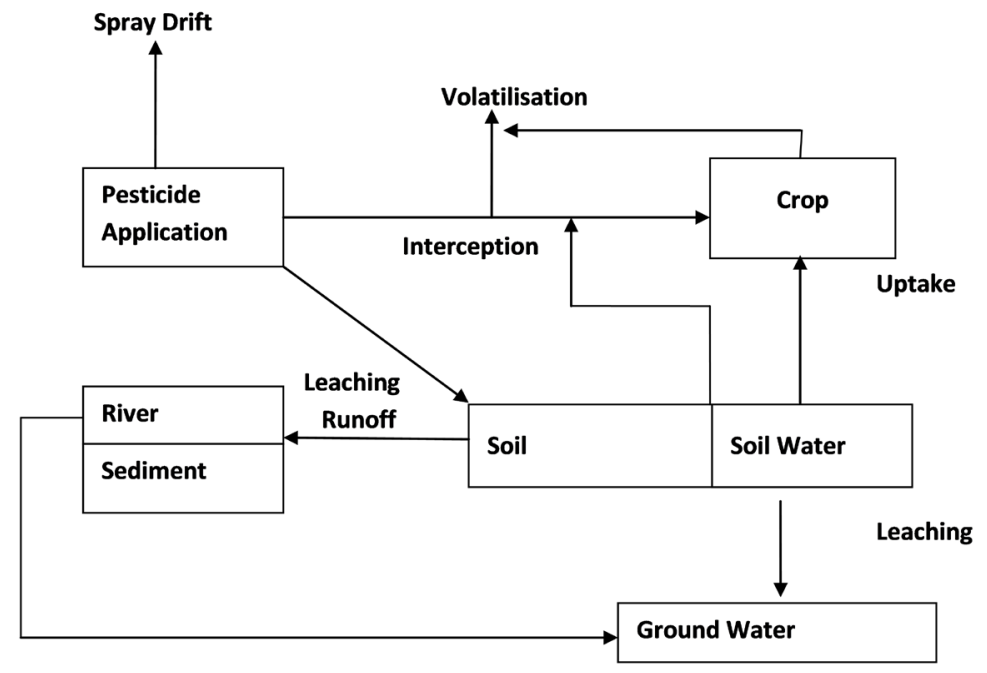

Fig. 1: Pathway of pesticide applied in soil.

\section{Sorption}

Pesticide is attached to the soil surface by the process called Sorption. The sorption is a complex phenomenon and is measured in terms of Sorption coefficient $K_{d}$.

$\mathrm{K}_{\mathrm{d}}=$ Concentration of chemical in soil/Concentration of chemical substance in water

A higher value of $K_{d}$ indicates that the pesticide is more strongly sorbed to soil and less concentration of it is in water present between soil particles.

Values for Kd vary greatly because the organic content of soil is not considered in the equation. Since adsorption occurs predominantly by partition into the soil organic matter, it is more useful to normalize the $\mathrm{K}_{\mathrm{d}}$ to the organic carbon content of a soil and express the distribution coefficient in $\mathrm{K}_{\mathrm{oc}}$. $\mathrm{K}_{\mathrm{oc}}$ is known as organic carbon-water partition co-efficient:

Koc or Kfoc $=(K d * 100) / \%$ Organic carbon

The value of $K_{d}$ is dependent on the physio-chemical properties of both soil and pesticide. These contaminants are easily absorbed in soil due to the competition of water with pesticide for binding sites in moist soil. Soils high in clay adsorb more pesticides because of presence of high ratio of chemical active sites on the surface of clay (Kerle et al., 2007). Organic matter present in the soil also increase the sorption of pesticides. In a given soil type, the polarity and the water solubility of pesticide determine its sorption coefficient. The sorption of neutral pesticides has been extensively investigated (Gao et al., 1998).

\section{Degradation}

Half life is the term used for Pesticide persistence. This is the length of time required for one-half of the original quantity to break down. For example, if a pesticide has a half-life of 15 days, 50 percent of the pesticide applied will still be present 15 days after application and half of that amount ( 25 percent of the original) will be present after 30 days. So the longer half-life means the greater the potential for pesticide movement. On the basis of half life pesticides can be divided into three categories as non persistent pesticides with a typical soil half-life of less than 30 days, moderately persistent pesticides with a typical soil half-life of 30 to 100 days, or persistent pesticides with a typical soil half-life of more than 100 days. The half-life of a few pesticides is given in Table 1.

The breakdown of pesticide in the environment could be chemical, light-induced or by microorganism. Besides the chemical nature of pesticide itself the rate of degradation depends upon environmental conditions such as temperature, humidity, salinity, $\mathrm{pH}$, nutrition, carbon dioxide, oxygen, substrate concentration, surfactant (Sartoros et al., 2005; Kah et al., 2007) as well as soil characteristics, most importantly microbial activity (Rao et al., 1983). A number of studies examining the relationship between sorption of pesticide and its degradation rate in various soils are available (Bolan and Baskaran, 1996; Baskaran et al., 1996; Dyson et al., 2002). It is found that when other factors are attuned, the sorption and degradation are negatively correlated (Guo et al., 2000), largely due to decreased concentration of freely available

Table 1: The properties of some selected pesticides useful for predicting environmental fate to cover entire range of the properties

\begin{tabular}{lllllll}
\hline Pesticide & Half-life (days) & $\begin{array}{l}\text { Sorption } \\
\text { coefficient Koc }\end{array}$ & Movement rating & $\begin{array}{l}\text { Water solubility } \\
\text { mg/l }\end{array}$ & $\begin{array}{l}\text { Vapor pressure } \\
\text { index }\end{array}$ & $\begin{array}{l}\text { Henry's Law Index } \\
\text { Kh** }\end{array}$ \\
\hline Malathion & 1 & 1800 & extremely low & 130 & 80 & 1000 \\
Benomyl & 67 & 900 & Low & 2 & 0.001 & 0.78 \\
Diuron & 90 & 480 & Moderate & 42 & 0.69 & 21 \\
Prometon & 500 & 150 & very high & 720 & 77.3 & 130 \\
\hline
\end{tabular}

*Vapour Pressure (Pv) is defined as the pressure that a chemical in the gas phase exerts over a surface. This surface can be water or dry soil. At room temperature, Pv values can range from 10-s to $300 \mathrm{~mm}$ of $\mathrm{Hg}$ (mercury). To make the value of Pv easier to read, the vapor pressure values is multiplied by $10^{7}$ and is called vapor pressure index

${ }^{* *} \mathrm{~K}_{\mathrm{h}}$ is defined as the air-water partition coefficient, which is calculated as the ratio of the partial pressure of a compound in air to the concentration of the compound in water at a given temperature under equilibrium. 
Table 2: Factors and processes increasing pesticide movement offsite (Gish et al., 2011).

\begin{tabular}{ll}
\hline Component & Factors \\
\hline Pesticide characteristics & Vapor pressure \\
& Water solubility \\
& Sorption coefficient \\
Salf life & soil water contents \\
& Organic matter content \\
& Soil texture \\
& Bulk density \\
& pH \\
& Precipitation \\
Meteorology & Humidity \\
& wind velocity \\
& Turbulence \\
& Temperature \\
& Solar Radiation \\
& Application method \\
& Application rates \\
& Pesticide formulation \\
\hline
\end{tabular}

pesticide. Organochlorine pesticides, viz. DDT, a wildly used insecticide is degraded to dichlorodiphenyldichloroethane (DDD), and dichlorodiphenyldichloroethene (DDE) by micro-organisms through reductive dechlorination and dehydrochlorination (Walia and Dureja, 1993).

\section{Leaching}

Leaching is the movement of pesticides in water through the soil. Leaching occurs downward, upward, or sideways. Pesticides are leached through the soil by the effect of rain or irrigation water. Pesticide leaching is highest for weakly sorbing as well as less persistent compounds. A number of mathematical models are available for predicting leaching potential of pesticides are available (Persicani, 1996). All these models incorporate the physicochemical properties of the pesticide, the properties of the soil and the weather. According to Nicollas (1988), lipophilicity is the most important physico-chemical property influencing the movement of un-ionised pesticides through soil. Water solubility is usually only an important factor in leaching for a few moderately polar solids with high melting points. Organic matter content is the most important property of the soil for un-ionised pesticides whilst the mobility of weak acids depends on soil $\mathrm{pH}$. Permanent anions and weak acids can be very weakly adsorbed and hence might easily reach groundwater. Applications in autumn are more likely to reach groundwater than those in spring because soil temperatures are low in spring and rainfall exceeds evaporation in winter due to decrease in humidity, enabling mobile pesticides to penetrate to sub soils where degradation rates can be very slow.

\section{Factors affecting distribution of pesticide}

Pesticide partitioning between these three phases is primarily a function of pesticide chemistry, pesticide formulation, soil properties, and local metrological conditions (Table 2). The rate at which pesticides are lost from these three pathways is influenced by a number of small-scale factors like soil moisture content, organic matter content, soil hydraulic properties, as well as large-scale influences such as wind speed profiles, agricultural management practices, timing of rainfall events relative to application, and field slope.

\section{Conclusion}

By taking into account all the factors influencing movement of pesticides and hence its availability in the environment, the optimal dosage, time and method of application of a particular pesticide can be adjusted according to local weather conditions and soil properties. Optimum dosage and appropriate timing of application ensures that there is minimum pesticide lends in the environment Thereby the risk posed by inherent hazardous nature of crop protection chemicals can be minimised.

\section{References}

Agnihotri, N.P., Gajbhiye, V.T., Mohapatra, S.P., Mukesh, K. and Kumar, M. 1994. Organochlorine insecticide residues in Ganga River water near Farrukhabad, India. Environmental Monitoring and Assessment 30(2): 105-112.

Baskaran, S., Bolan, N.S., Rahman, A. and Tillman, R.W. 1996. Effect of exogenous carbon on the sorption and movement of atrazine and 2, 4-D by soils. Australian Journal of Soil Research 34: 609-622.

Bolan, N.S. and Baskaran, S. 1996. Biodegradation of 2, 4-D herbicide as affected by its adsorption-desorption behaviour and microbial activity of soils. Australian Journal of Soil Research 34: 1041-1053.

Cousins, I.T., Beck, A.J. and Jones, K.C. 1999. A review of the processes involved in the exchange of semi-volatile organic compounds (SVOC) across the air-sol interface. Science of the Total Environment 228: 5-24.

Doull, J. 1989. Pesticide carcinogenicity. In: Ragsdale, N. and Menzer, R.E. (Eds.) Carcinogenicity and pesticides: Principles, issues and relationships. ACS, Washington, DC, pp. 1-5.

Dwivedi, S., Mishra, S. and Tripathi R.D. 2018. Ganga water pollution: A potential health threat to inhabitants of Ganga basin. Environment International 117: 327-338.

Dyson, J.S., Beulke, S., Brown, C.D. and Lane, M.C.G. 2002. Adsorption and degradation of the weak acid mesotrione in soil and environmental fate implications. Journal of Environmental Quality 31: 613-618.

FICCI 2018. Knowledge Paper Agrochemicals. http://ficci.in/ spdocument $/ 23002 /$ Knowledge $\% 20$ Paper $\% 20$ Agrochemicals $\% 20$ 2018.pdf

Gao, J.P., Maguhn, J., Spitzauer, P. and Kettrup, A., 1998. Sorption of pesticides in the sediment of the Teufelsweiher pond (Southern Germany). I: equilibrium assessments, effect of organic carbon content and pH. Water Research 32(5): 1662-1672.

Gish, T.J., Williams, J., Prueger, J.H., Kustas, W., McKee, L.G. and Russ, A. 2011. Pesticide Movement. Publications from USDA-ARS/UNL Faculty, pp. 1337.

Guo, L., Jury, W.A., Wagenet, R.J. and Flury, M. 2000. Dependence of pesticide degradation on sorption: Nonequilibrium model and application to soil reactors. Journal of Contaminant Hydrology 43(1): 45-62.

Jin-Clark, Y., Lydy, M.J. and Zhu, K.Y. 2002. Effects of atrazine and cyanazine on chlorpyrifos toxicity in Chironomus tentans (Diptera: Chironomidae). Environmental Toxicology and Chemistry 21: 598-603.

Jury, W.A. and Flühler, H. 1992. Transport of chemicals through soil: Movement, models, and field application. Advances in Agronomy 47: 141-202.

Kah, M., Sabine, B. and Colin, D.B. 2007. Factors influencing degradation of pesticides in soil. Journal of Agricultural and Food Chemistry 55: 4487-4492.

Kerle, E.A., Jenkins, J.J. and Vogue, P.A. 2007. Understanding pesticide persistence and mobility for groundwater and surface water protection. Oregon State University Extension Service, EM8561-E.

Kumar, A.D. and Narasimhareddy, D. 2017. High Pesticide use in India: Health Implications. Health Action, pp. 7-12

Mesnage, R. and Séralini, G.-E. 2018. Toxicity of pesticides on health and environment. Frontiers in Public Health 6: 268. 
Nicholls, P.H. 1988. Factors influencing entry of pesticides into soil water, Presented at the symposium 'Pesticides in surface and groundwater' on 10 February 1987. https://doi.org/10.1002/ps.2780220204

Nicolopoulou-Stamati, P., Maipas, S., Kotampasi, C., Stamatis, P. and Hens, L. 2016. Chemical Pesticides and Human Health: The Urgent Need for a New Concept in Agriculture. Frontiers in Public Health 4: 148.

Persicani, D. 1996. Pesticide leaching into field soils: sensitivity analysis of four mathematical models. Ecological Modelling 84(1-3): 265-280.

Rao, P.S.C., Mansell, R.S., Baldwin, L.B. and Laurent, M.F. 1983. Pesticides and their Behaviour in Soil and Water. Soil Science Fact Sheet. Florida Cooperative Extension Service, Institute of Food and Agricultural Sciences, University of Florida, Gainesville, FL.

Rial-Otero, R., Cancho-Grande, B., Arias-Estevez, M., Lopez-Periago, E. and Simal-Gandara, J. 2003. Procedure for the measurement of soil inputs of plant-protection agents washed off through vineyard canopy by rainfalls. Journal of Agricultural and Food Chemistry 51 (17): 5041-5046.

Sartoros, C., Yerushalmi, L., Béron, P. and Guiot, S.R. 2005. Effects of surfactant and temperature on biotransformation kinetics of anthracene and pyrene. Chemosphere 61: 1042-1050.
Sparling, D.W., Fellers, G.M. and McConnell, L.L. 2001. Pesticides and amphibian population declines in California, USA. Environmental Toxicology and Chemistry 20: 1591-1595.

Taylor, A.W. and Spencer, W.F. 1990. Volatilization and vapor transport processes. In: Cheng, H.H. (Ed.) Pesticides in the soil environment: Processes, impacts, and modelling. SSSA Book, pp. 213269.

USEPA, 1990. Pesticides in Ground Water, U.S. Department of the Interior, U.S. Geological Survey. https://pubs.usgs.gov/fs/1995/0244/report. pdf.

Walia, S. and Dureja, P. 1993. Photochemical and microbial degradation of insecticide Pestic. Res. J. 5(2): 133-150.

Wania, F. 2003. Assessing the potential of persistent organic chemicals for long-range transport and accumulation in Polar Regions. Environmental Science and Technology 37: 1344-1354.

Yadav, S. and Dutta, S. 2019. A study of pesticide consumption pattern and farmer's perceptions towards pesticides: A case of Tijara Tehsil, Alwar (Rajasthan). International Journal of Current Microbiology and Applied Sciences 8(4): 96-104. 